\title{
Combination of radiotherapy and sorafenib in recurrent hepatocellular carcinoma: a case report
}

\author{
Yaoru Huang ${ }^{1}$, Shang-Wen Chen ${ }^{2,}{ }^{3}$, Chia-Chun Kuo ${ }^{1}$, Jeng-Fong Chiou ${ }^{1,3}$ \\ 1. Department of Radiation Oncology, Taipei Medical University Hospital, Taipei, Taiwan. 2. Department of Radiation \\ Oncology, China Medical University Hospital, Taichung, Taiwan. 3. Department of Radiology, School of Medicine, College \\ of Medicine, Taipei Medical University, Taipei, Taiwan. \\ Correspondence: Jeng-Fong Chiou. Address: Department of Radiation Oncology, Taipei Medical University Hospital, \\ No.252, Wu Hsing Street, Taipei City 110, Taiwan. Email: sjfchiou@gmail.com
}

Received: J une 4, 2014

DOI : $10.5430 /$ crcp.v1n2p155
Accepted: J une 24, 2014

URL: http://dx.doi.org/10.5430/crcp.v1n2p155

\section{Abstract}

In patients with unresectable hepatocellular carcinoma (HCC), radiotherapy is considered for patients with a large tumor burden or tumors with portal vein tumor thrombosis, which is not indicated for operation or transarterial chemoembolization. Sorafenib has proved to be effective as a first-line treatment for locally advanced and metastatic HCC. Preclinical and clinical studies have shown the efficacy of the combined therapeutic effects of radiotherapy (RT) with sorafenib used either concurrently or sequentially. We presented a patient with multiple recurrent HCCs successfully treated with combined RT and sorafenib.

\section{Key words}

Hepatocellular carcinoma, Radiation therapy, Sorafenib

\section{I ntroduction}

Hepatocellular carcinoma (HCC) is a common cause of cancer death in Asia ${ }^{[1]}$. Most patients present with advanced disease, which is not suitable for surgical resection, or liver transplant. Percutaneous ethanol injection, radiofrequency ablation, and transcatheter arterial chemoembolization (TACE) are generally effective for patients with small tumor, superficial location, or limited lesions ${ }^{[2]}$. Currently, radiotherapy (RT) with or without TACE is considered for patients with a larger tumor burden ${ }^{[3,4]}$, or tumors with portal vein tumor thrombosis (PVTT) ${ }^{[5]}$; owing to TACE is not effective for larger tumor burden and contraindicated for PVTT. Sorafenib, a potent multikinase inhibitor with antiangiogenic and antiproliferative properties, has proved to be effective as a first-line treatment for locally advanced and metastatic $\mathrm{HCC}^{[7,8]}$. To recognize the combined therapeutic effects of RT with sorafenib used either concurrently or sequentially for unresectable tumors, a phase 2 study showed that combined treatment can achieve a 2-year overall survival and infield progression free survival of $32 \%$ and $39 \%$, respectively ${ }^{[6]}$. To test the efficacy of this combination, we presented a patient with multiple recurrent HCCs treated with combined RT and sorafenib.

\section{Case report}

A 64 year-old male had a past history of hepatitis B virus-associated HCC. He received segmental hepatectomy in October 2008. However, intrahepatic recurrence (tumor size, $1.3 \mathrm{~cm} \times 1.1 \mathrm{~cm}$ ) was found by computed tomography (CT) scan in 
May 2012. After that, he received three courses of TACE between May 2012 and October 2012. Although complete remission had been achieved, 4 new recurrent nodules adjacent to the tumor beds were found through the follow-up magnetic resonance image (MRI). The maximal diameter for these tumors was $4.2 \mathrm{~cm}$ at segment 8 (previous TACE area) with coexisting right PVTT, $0.6 \mathrm{~cm}$ at segment $4,1.6 \mathrm{~cm}$ at segment 8 near inferior vena cava, and $1.2 \mathrm{~cm}$ at segment 5 , respectively (see Figure 1). Because another course of TACE was not recommended due to multiple recurrences, he became a participant of a clinical trial investigating the efficacy of combined sorafenib and RT. Prior to the treatment, his baseline data is listed in the table. The pretreatment liver function was within normal range. Child-Turcotte-Pugh score was classified as 5 (class A). The value of serum alfa-fetoprotein was $2.0 \mathrm{ng} / \mathrm{ml}$. The Cancer of the Liver Italian Program (CLIP) score was 1.

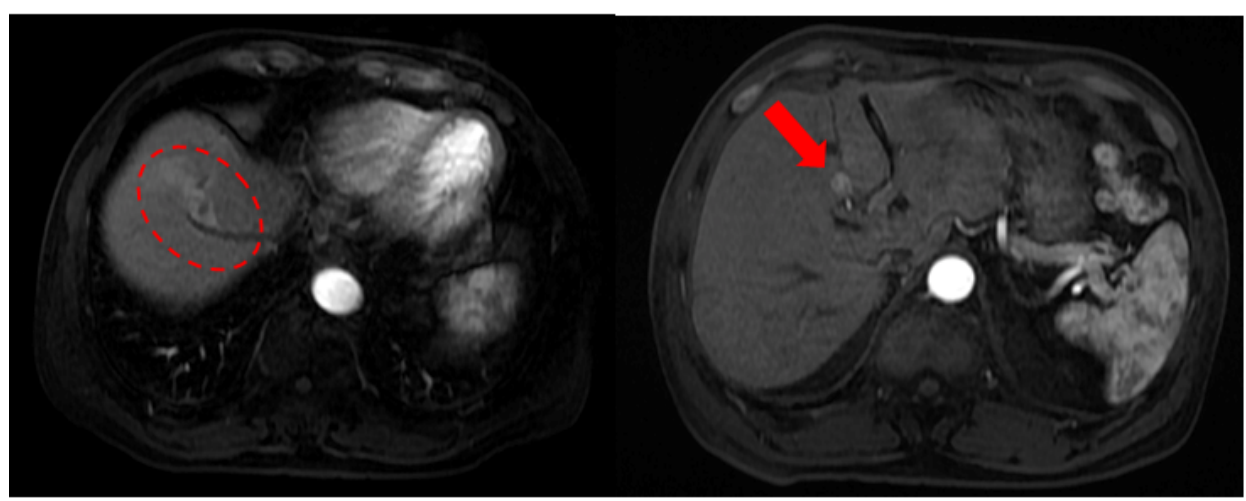

Figure 1. A 64 year-old male had hepatocellular carcinoma (HCC) s/p segmental hepatectomy, then with 1st recurrence with one recurrent nodule $\mathrm{s} / \mathrm{p}$ trans-arterial embolization for three times; then with 2 nd recurrence with 4 recurrent nodules shown as above. Magnetic Resonance Image (MRI) on 2012/11/28 showing a $4.2 \mathrm{~cm}$ tumor with right portal vein tumor thrombosis (PVTT) of T1 volume acceleration-flexible (LAVA) with contrast (left) and another one, $1.2 \mathrm{~cm}$ in size, at segment 5 (right).

Table. Lab data before and during concurrent radiotherapy with sorafenib during 2012/11/28 12/21

\begin{tabular}{llllll}
\hline & $\mathbf{2 0 1 2 / 1 1 / 2 5}$ & $\mathbf{1 2 / 0 3}$ & $\mathbf{1 2 / 1 0}$ & $\mathbf{1 2 / 1 7}$ & $\mathbf{1 2 / 2 0}$ \\
\hline White blood count $(/ \mathrm{ul})$ & 3840 & 3540 & 2990 & 2990 & 5990 \\
Hemoglobin $(\mathrm{g} / \mathrm{dl})$ & 14 & 14.7 & 15.1 & 14.9 & 14.4 \\
Platelet $\left(* 10^{3}\right)$ & 103 & 116 & 96 & 89 & 62 \\
INR & 1.17 & 1.07 & & & \\
Creatinine $(\mathrm{mg} / \mathrm{dl})$ & 0.9 & 0.9 & 0.9 & 0.9 & 0.7 \\
AST/ALT (U/L) & $25 / 18$ & $39 / 24$ & $51 / 32$ & $49 / 29$ & $43 / 28$ \\
Biirubin toal (mg/dl) & 0.6 & 1.4 & 1.2 & 1.3 & 2.4 \\
Albumin $(\mathrm{g} / \mathrm{dl})$ & 4 & & 3.7 & 3.8 & \\
CTP score & 5 (class A) & 5 (class A) & 5 (class A) & 5 (class A) & 6 (class A) \\
\hline
\end{tabular}

The clinical target volume (CTV) encompassed the area of the 4 tumors and adjacent PVTT. Normal liver was defined as the whole liver volume minus the CTVs. The calculated value for the CTV was $50 \mathrm{ml}$, while the normal liver reserve was 1,081 ml. Between November 2012 and December 2012, this patient was treated with Tomotherapy (TomoTherapy Inc., Madison, WI) and daily image-guided technique. The prescribed dose was $50 \mathrm{~Gy}$ in 20 fractions (see Figure 2). Sorafenib was started from the commencement of RT. The starting dose was $600 \mathrm{mg}$ daily. Using the National Cancer Institute Common Terminology Criteria for Adverse Events (CTCAE version 4.0) ${ }^{[9]}$, grade 2 hand-foot skin reaction was observed soon after radiation therapy. As a result, the dose of sorafenib was reduced to $400 \mathrm{mg}$ daily; the patient continued in the maintenance stage of sorafenib with the dosage of $400 \mathrm{mg}$ daily till now. Follow-up MRI showed complete remission of the tumors (see Figure 3), and no recurrence was found until the latest MRI in March 2014. 


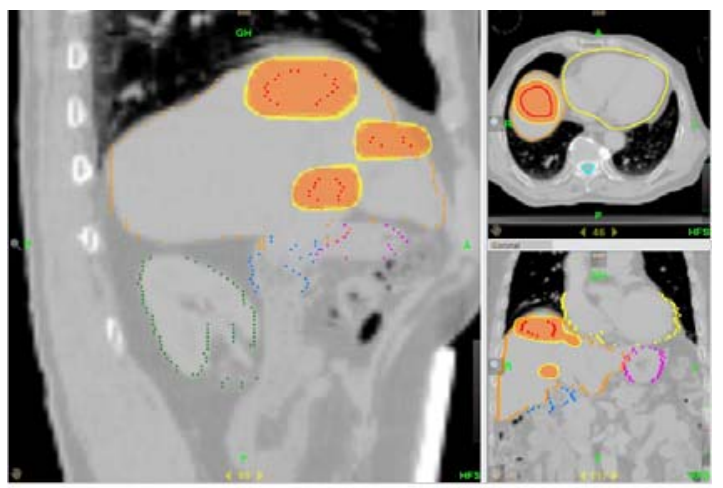

Figure 2. Dose distribution of radiotherapy to recurrent HCC nodules

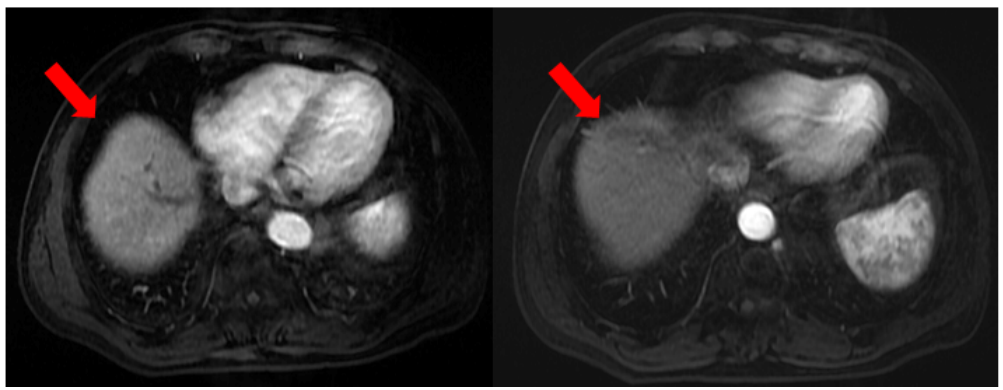

Figure 3. MRI T1 LAVA with contrast on 2013/03/01 (left) and 2014/03/04 (right) showed complete remission and no further recurrence

The liver toxicity from the combined treatment was grade 2 hyperbilirubinemia. The pretreatment total bilirubin had risen to the peak of $2.4 \mathrm{mg} / \mathrm{dl}$ during the 4 th week of RT. Then, the value returned to the normal range two weeks after RT. The serum levels of albumin and transaminases, as well as prothrombin time, were not more than their normal ranges during the RT course and thereafter. Sorafenib-related grade 2 hand-foot skin reaction was observed after starting treatment, but downgraded to grade 1 soon following dose reduction. The other treatment-related adverse effects, such as gastrointestinal symptoms were not obvious throughout the whole course of treatment.

\section{Discussion}

Sorafenib-mediated blockage of the Raf/MAPK and VEGF receptor pathways might enhance the efficacy of RT. RT followed sequentially by sorafenib was associated with the greatest tumor growth delay ${ }^{[10]}$. The ideal combined modality approach to treating unresectable HCC may involve RT administered concurrently with a radiosensitizing agent followed by maintenance sorafenib therapy ${ }^{[11]}$. Thus, it would be interesting to disclose the role of sorafenib used concurrently with or after RT.

The major concern of sorafenib used concurrently with RT was the treatment-related toxicities. According to the result of a phase 2 trial ${ }^{[6]}$, hepatic toxicities are a major determinant of the safety when using combined treatment. Six out of 40 patients (15\%) developed grade 3 or higher hepatotoxicities and 3 were fatal. Because sorafenib-induced severe hepatitis has been described ${ }^{[12]}$, the synergistic effect of sorafenib-induced liver toxicity cannot be ignored. Therefore, case selection, as well as a sophisticated RT scheme, is imperative to optimize therapeutic outcome for patients with advanced HCC requiring treatment. For example, a CLIP score $>2$ can be used for predicting poor therapeutic outcome ${ }^{[6]}$. In addition, patients with poor baseline liver function should be treated with caution.

Huang et al. demonstrated that a prescribed RT dose of $\geq 50$ Gy to the area of PVTT is able to achieve an overall response rate of $25 \%{ }^{[15]}$. They also reported that the median survival for the complete responders could reach 13 months. With the 
evolution of new RT techniques, currently stereotactic body RT has been suggested to be a treatment of choice in patients with unresectable HCC, especially for tumors with maximal diameter less than $6 \mathrm{~cm}$, or tumor volumes smaller than 100 $\mathrm{ml}^{[13,14]}$. Accordingly, the therapeutic outcome of RT could be increased. In this patient, although 4 lesions were irradiated simultaneously, the maximal tumor diameter was less than $6 \mathrm{~cm}$ and the treatment volume was limited. In addition, coexisting tumor thrombosis was confined to a small branch of right portal vein. Owing to the limited tumor burden, the treatment response to this combination was excellent. Furthermore, the liver function was well preserved due to a satisfactory pretreatment liver reserve.

Given the efficacy and toxicities of combined RT and sorafenib concurrently and sequentially has been reported ${ }^{[6]}$, our case report may have implications for decision-making when initiating the similar treatment for patients with unresectable HCC refractory to further local treatment. Of course, appropriate case selection is pivotal to promote the treatment outcome. Further clinical trials with a stratification of patients are required to validate the therapeutic effect of this combination.

\section{Reference}

[1] Jemal A, Bray F, Center MM, et al. Global cancer statistics. Ca Cancer J Clin. 2011; 61: 69-90. PMid: 21296855.

http://dx.doi.org/10.3322/caac.20107

[2] Bruix J, Sherman M. Management of Hepatocellular Carcinoma: An Update. Hepatology. 2011; 35: 1020-1055. PMid: 21374666. http://dx.doi.org/10.1002/hep.24199

[3] Hawkins MA, Dawson LA. Radiation therapy for hepatocellular carcinoma: from palliation to cure. Cancer. 2006 ; 106 : $1653-1663$. PMid: 16541431. http://dx.doi.org/10.1002/cncr.21811

[4] Cheng JC, Chuang VP, Cheng SH, et al. Local radiotherapy with or without transcatheter arterial chemoembolization for patients with unresectable hepatocellular carcinoma. Int J Radiat Oncol Biol Phys. 2000; 47: 435-442. http://dx.doi.org/10.1016/S0360-3016(00)00462-4

[5] Yamada K, Izaki K, Sugimoto, K, et al. Prospective trial of combined transcatheter arterial chemoembolization and threedimensional conformal radiotherapy for portal vein tumor thrombus in patients with unresectable hepatocellular carcinoma. Int $\mathrm{J}$ Radiat Oncol Biol Phys. 2003; 57: 113-119. http://dx.doi.org/10.1016/S0360-3016(03)00434-6

[6] Chen SW, Lin LC, Kuo YC, et al. Phase 2 study of combined sorafenib and radiation therapy in patients with advanced hepatocellular carcinoma. Int J Radiat Oncol Biol Phys. 2014; 88 (5): 1041-7. PMid: 24661657. http://dx.doi.org/10.1016/j.ijrobp.2014.01.017

[7] Llovet JM, Ricci S, Mazzaferro V, et al. Sorafenib in advanced hepatocellular carcinoma. N Engl J Med. 2008; 359: 378-390. PMid: 18650514. http://dx.doi.org/10.1056/NEJMoa0708857

[8] Cheng AL, Kang YK, Chen Z, et al. Efficacy and safety of sorafenib in patients in the Asia-Pacific region with advanced hepatocellular carcinoma: a phase III randomised, double-blind, placebo controlled trial. Lancet Oncol. 2009; 10: 25-34. http://dx.doi.org/10.1016/S1470-2045(08)70285-7

[9] NCI. Common Terminology Criteria for Adverse Events version 4.0 (CTCAE). 2009. Available from: http://ctep.cancer.gov/forms/CTCAEv4.pdf (accessed May, 2009).

[10] Plastaras JP, Kim SH, Liu YY, et al. Cell cycle dependent and schedule-dependent antitumor effects of sorafenib combined with radiation. Cancer Res. 2007; 67: 9443-9454. PMid: 17909054. http://dx.doi.org/10.1158/0008-5472.CAN-07-1473

[11] Wild AT, Gandhi N., Chettiar ST, et al. Concurrent versus Sequential Sorafenib Therapy in Combination with Radiation for Hepatocellular Carcinoma. PLOS ONE. 2013; 8: e65726. PMid: 23762417. http://dx.doi.org/10.1371/journal.pone.0065726

[12] Llanos L, Bellot P, Zapater P, et al. Acute hepatitis in a patient with cirrhosis and hepatocellular carcinoma treated with sorafenib. American J Gastroenterol. 2009; 104: 257-258. PMid: 19098892. http://dx.doi.org/10.1038/ajg.2008.41

[13] Andolino D, Johnson CS, Maluccio M, et al. Stereotactic body radiotherapy for primary hepatocellular carcinoma. Int J Radiat Oncol Biol Phys. 2011; 81: 447-453. PMid: 21645977. http://dx.doi.org/10.1016/j.ijrobp.2011.04.011

[14] Seo YS, Kim MS, Yoo SY, et al. Prelimary result of stereotactic body radiotherapy as a local salvage treatment for inoperable hepatocellular carcinoma. J Surg Onco. 2010; 102 (3): 209-214. PMid: 20740576. http://dx.doi.org/10.1002/jso.21593

[15] Huang YJ, Hsu HC, Wang CY et al. The treatment response in cases of radiation therapy to portal vein thrombosis in advanced hepatocellular carcinoma. Int J Radiat Oncol Biol Phys. 2009; 73: 1155-1163. PMid: 18760547.

http://dx.doi.org/10.1016/j.ijrobp.2008.06.1486 